\title{
Challenges Analysis Security for Cloud Computing
}

\author{
Asmaa Shaker Ashoor \\ University of Babylon, Iraq \\ asmaa@uobabylon.edu.iq
}

\begin{abstract}
The Web has become an imperative prerequisite for existence, and cloud computing is a new innovation that has gotten to be the center of the research since of its capacity to decrease the costs related to cloud computing. And everybody presently works beneath the cloud computing environment, social media, companies, government offices, and clients. But at the same time, this sort of innovation faces security challenges that incorporate data confidentiality, data integrity, and availability. For that, numerous control included inside the cloud, and in case we are not arranged together, we don't understand the advantages. Cloud computing disposes of the require of having a total Foundation of equipment and software to meet clients necessities and applications. This paper points to explain types of cloud, security models of cloud, essential challenges of the cloud, the advantages of the cloud, analysis protection and security for the cloud.
\end{abstract}

Key words : Cloud Computing, Security, Challenges, IaaS, PaaS, SaaS.

\section{INTRODUCTION}

Cloud computing has become one of the important technologies utilized, which given an assortment of ways to get to resources and manage information technology in a wide variety of areas [2][1]. Cloud computing comprises of frameworks like a service "IaaS", platform as a service "PaaS", also software as a service "SaaS", and through these foundations, cloud computing works on sharing resources by providing a simplified model of infrastructures[3][4]. Cloud computing is an imperative modern innovation, but it has confronted numerous dangers and dangers in different ways. Since of the adaptability of cloud computing and the ease of getting to resources through its widespread deployment, it disposed of the require for extra hard drives and the assignment of memory space. The stored and widespread data can be accessed widely and in imperative areas and wherever it is found since cloud computing is distributed systems and so the outside information will be surrounded by a high- security situation to avoid any potential threats by intruders to this data. Cloud computing benefit suppliers proceed to supply solutions to security issues, for example, "security, privacy, reliability, legal issues, open standards, compliance, flexibility, and the capacity stay for a long time"[3][5]. Cloud computing is a system for getting to the data and services through the utilize of technologies and the Web, which can permit proceeded communication between clients and the server[6][7]. Cloud computing is used for authorizing worldwide get to share with groups like administrations, apps, information, servers, and computer systems. This leads to a more reliable and efficient data access process, thus providing a clear and structured effort. The task of developing the cloud depends on the achievement of resources and the economy compared to the benefits and their cost effectiveness and appropriateness and thus will be the appropriate choice for many huge and small companies.

\section{LITERATURE REVIEW}

Cloud computing is made up of logical entities represented by data and software and get to it through the Web, and these substances required consent to introduce on the client machine. Be that as it may, the matter differs by the presence of the client server program, which is able to permit for large storage capacity, hence providing clients with hosting programs and applications containing data and information for work entities. There are a lot of secure algorithms that have been applied to cloud computing technologies, but numerous have been unsuccessful to fathom the issue of persistent security threats. There are numerous researchers who have made a several recommendations that incorporate secure information security procedures within cloud computing. Various studies have been achieved related security case in cloud computing from different points of opinion. Cong [8]suggested a scheme of integration of storage correctness protections and information blunder localization. The suggested scheme is effective and flexible, against malicious information adjustment attack, and server conspire attacks.

Gellman proposed the collection, maintenance, and disclosure of personal information by means of cloud computing. While Jarabek and Hyde discussed the possibility of attacks on data and information on cloud computing[9][10]. Kresimir et al, addressed the high level of security concerns in the cloud computing model[11]. J. Bethencourtet al, presented the features Based Scheme (ABE). In this manner the client will have the qualities in addition to its unique ID. He explained that there are two groups of "In key-policy and Cipher text-policy " [12]. Omer K. Jasim et al. Explain "symmetric encryption key algorithms and various asymmetric key algorithms". The role of cryptographic algorithms for the cloud computing 
environment for different input categories was discussed and clarified how changes to the size of existing files are completed[13]. Bernd et al, presented the weaknesses in the main model of cloud computing and how they influence client information.

\section{TYPES OF CLOUD COMPUTING}

Cloud computing is a combination of hardware and software that provides services to clients across different communication network Figure1 explain "cloud computing" types. Four types of the cloud in there:

1. Public Cloud: It is the open utilize by clients to get to services and applications and in this way the capacity to supply cloud computing infrastructure for numerous clients and third-party administration and the capacity of numerous companies and institutions to work on the provided infrastructure.

2. Private cloud: It is the capacity of numerous consumers (services and applications) to get to them inside the organization. This implies that the cloud computing infrastructure will be accessible to a particular client and managed by the organization itself or through a third-party service supplier or interior and exterior the organization, which is a private network that is represented by the virtualization simulation of the equipment[14].

3. Community Cloud: This type of cloud is designed to allow a particular gather inside the organization to get to numerous services and applications. It is conceivable to hold a meeting and manage the organization inside this type of cloud whether they are interior the organization or exterior it. This needs to provide security and privacy.

4. Hybrid Cloud: This type of cloud comprises of two or more types of hybrid cloud infrastructure, which is "open cloud and private cloud" and allows the transfer of data and applications being linked together with a unified or private technology.

\section{CLOUD COMPUTING SECURITY MODELS[15]}

Cloud computing services will be available through three models illustrated in Figure 1:

1. Infrastructure as a Service "IaaS" Cloud Computing Security Model. This foundation gives the capacity and organizing components to cloud organizing. It depends intensely on application programming interfacing"APIs" to permit undertakings to oversee and connected with the cloud. Be that as it may, cloud APIs tend to be unreliable as they're open and promptly available on the organize. The enterprise's security commitments incorporate the rest of the stack, counting the applications. Conveying network packet brokers "NPB" in an "IaaS" environment gives the visibility into security issues inside a cloud arrange. "NPB's" coordinate trials and information to the fitting "network performance management "NPM" and security devices. At the side conveying "NPB" to assemble wire information, undertakings ought to log wires to see issues happening at the endpoints in a organize. "IaaS" moreover gives get to crucial assets such as physical machines,

virtual machines, virtual capacity. Amazon's EC2 is most "IaaS" suppliers.

"IaaS" cloud computing benefit models require these extra security highlights:

- The virtual web application firewalls in front of the website for protection from malware.

- Network-based virtual firewalls at the edge of the cloud, which protect their surroundings.

- Virtual routers

- Intrusion Detection Systems and Intrusion Prevention Systems "IDS/IPS" Network segmentation.

2. Software as a Service "SaaS" Cloud Computing Security Model

"SaaS" has program and information that are open by means of a browser. Cloud Get to Security Brokers "CASB" It has a central role in finding security problems within the "SaaS" program for the benefit of the cloud. On the other hand, it works to $\log$ in, comment and provide control including the ability to encrypt. "SaaS" gives program application as a benefit for clients Client Relationship Administration "CRM" applications ,Offer assistance Work area Applications, Human Asset "HR" Arrangements are a few applications given by "SaaS". Other security highlights for the "SaaS" cloud environment incorporate:

•"Logging" • •IP restrictions" • •API gateways"

3. Platform as a Service "PaaS" Cloud Computing Security Model

"PaaS" as "deployment of applications without the taken a toll and complexity of buying and overseeing the fundamental equipment and computer programs and provisioning facilitating capabilities." the security of applications rests with the undertaking. "PaaS" display the environment for numerous applications. Advancement \& sending devices, required to create application can be given. It incorporates a feature of point-and click instruments that permit non-developers to form web applications. Google Apps and Microsoft Windows Sky blue are for the most part known "PaaS" suppliers. The basic elements to secure the "PaaS" cloud involve:

$\cdot$ Logging $\quad \cdot$ IP restrictions $\quad \cdot$ API gateways

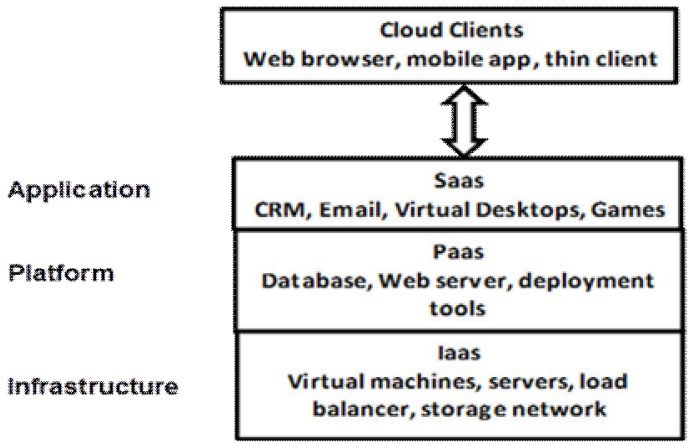

Figure 1: Cloud Computing Security Models 


\section{ESSENTIAL CHALLENGES OF CLOUD COMPUTING}

Six challenges to know before implementing cloud technology:

1. "Cost": The value of "cloud computing" is inexpensive, but configuring the platform, concurring to the company's necessities can be exorbitant. On the other hand, the cost of transferring data to other clouds is a special problem for small projects. Increased cloud service costs may come from the inability to control the development of the cloud computing system.

2. "Service Provider Reliability": Technical service provider capacity isn't different from cost services. The service provider can be reached by requesting this service. The focus of importance could be on support and service provider. Therefore, there has to be experienced in the knowledge the technologies, which the provider will monitor its services and therefore will protect the reliability necessities.

3. "Downtime": Downtime is major drawbacks in the cloud, as the platform cannot be guaranteed to be free of charge for processors. Cloud technology activates small businesses dependent on its network, so the potential require for companies with internet connectivity will be more careful before using the cloud.

4. "Password Security": The password is an important part of cloud security, as the more users the same password on your cloud account, the lower the security side. Thus, individuals who have your password will be able to access the data stored there. The use of authentication by companies and making sure that passwords are guaranteed and changed in an orderly manner when changing employees. The provision of passwords to users should be dedicated only to those who actually need them.

5. "Data privacy": Keeping sensitive and individual data within the cloud must be specified with the description that it is used only inside and cannot be shared with a third party. Companies must be arranged for the purpose of safely and effectively supervising the information they collect.

6. "Vendor lock-in": This state of affairs occurs when suppliers are changed in a costly and unpredictable manner. So it is better to have a better accession to the cloud agreement than to leave it. The reliability of services must be verified and transferred to another provider, as well as knowledge of the needs in general. Using the cloud is the best solution for many companies and is focusing on understanding what can be obtained.

\section{ADVANTAGES OF CLOUD COMPUTING}

Ten Advantages various of cloud computing in there[16]: 1. "Cost Savings": Cloud computing gives modality to utilize services like infrastructure, platform, etc. instituted upon needs, it makes to diminish the first cost, dodge the setting of high capability servers and others that are able of more than penniless one. It charges sum relied upon the usage of infrastructure, platform and other services, this helps customers to diminish the cost by indicating the exact necessities.

2. "Time Saving": Cloud computing's ability to reduce the time it takes to plan organizations by also facilitating activities at the same time, and this helps organizations save time. This would make the implementation of the hypothesis of the experiment start and then convert slowly to an unchangeable condition. On the other hand, it would make organizations able to start with a few numbers and rising to a situation which is growing very high.

3. "Scalability and Flexibility": Cloud computing offers the ability to adapt organizations to use resources even at peak times, and thus the ability to accept consumer demands. On the other hand, the ability of the cloud computing is ready to meet the necessary requirements, through configuration and setup with high-capacity servers.

4. "Backup and Recovery": Information is stored in the cloud, and backup and retrieval are less demanding than being placed on a physical device and the ability to retrieve information from potential disasters[17].

5. "Resource Maximization": Cloud computing has had a role in reducing IT resources for many organizations by intensifying resources from the Cloud Group. There are facilities provided by many suppliers to meet the requirements at any time. This is one of the important advantages of cloud computing[18].

6. "Mobile Access": The ability of cloud computing to reach the cloud that has a large capacity, as well as the ability of clients who have mobile devices to access the network and work on its applications through their presence at domestic and there is no need to go to the workplace or organization. On the other hand, the number of clients of mobile devices is higher compared to users of computers or other smart devices. Where clients can access their files or any other applications and by utilizing their mobile phones and from anywhere in the world, this increases the equipment dependence on cloud computing technology[19].

7. "Multisharing": Cloud computing shares many different applications and clients as it works as a distributor and participating simultaneously. Consequently, the work will be more productive and less costly by customers and different applications, and by sharing the common infrastructure [20]. 8. "Customization": The cloud platform allows clients to adapt to their needs and through redevelopment procedures. As well as presenting the basic system for creating applications and dealing with various characteristics to implement the required tasks and procedures [21].

9. "Collaboration": Different groups of employees provides larger projects and applications with each other. Cloud computing is a convenient way to work with groups of clients in an effective manner in a group environment or different applications.

10. "Deliver new services": Cloud computing provides services through"multi-national companies" such as "Amazon, Google, IBM, Microsoft, Salesforce.com". These companies provide facilities to present various applications and modern products with the same date of their issuance. 


\section{ANALYSIS PROTECTION AND SECURITY FOR CLOUD COMPUTING}

The data that's transmitted through the cloud computing must be encrypted for the reason of distributing them simultaneously and independently. Thus the possibility of securing the cloud data within the databases through encryption and by utilizing distinctive encryption methods including the utilize of symmetric keys and asymmetric keys. This method will guarantee the maintenance of confidentiality and data flowing through cloud computing. The security breaking of cloud computing is achieved by the attacker's pernicious programs. Among the foremost noticeable of these malicious attacks is "buffer overflow and thus freezing the operating system or program" and the other sort of attack is "an uncontrolled coordination chain that breaks a program or executes malevolent code." Hence, the update of systems will lead to the identification and prevention of these attacks. Business and authorities is always attempting to enhance Cloud surroundings so that an effort to decrease costs, enhance efficiencies and minimize administrative overhead. Here recommend a framework; which encrypts information earlier than it is uploaded on to the cloud and it additionally create secured, concurrent and impartial get right of entry to encrypted information over cloud. Thus, if used securely, cloud computing offers a person with exceptional advantages and overcomes its only drawback of safety threat.

\section{CONCLUSION}

The security of Cloud computing model must be thought about essentially for its success. Cloud computing technology offers a different of Advantages to the combines and organizations. In this paper, we have examined the different Advantages and types of computing. In addition, we have explained the major security of these technologies. Moreover, we have inspected essential challenges of cloud computing at that point we have recommended adopting computing procedures in accordance with analysing each the major security event, in cloud and analysis protection and security for cloud computing. A major disadvantage of cloud applications is the inability to provide an acceptable level of protection. On the other hand, the security side provides broadcasting channels, which may be from a third party. For the purpose of using the cloud intensely, many problems must be of use advantageous in a way, making sure the excessive stage of "security, confidentiality, authenticity, integration, agility, scalability and trust".

\section{ACKNOWLEDGEMENT}

The writers are grateful to the Babylon University, Iraq for submitting study means in achieves this paper.

\section{REFERENCES}

1. C. Wang, K. Ren, W. Lou, and J. Li. Toward publicly auditable secure cloud data storage services, IEEE Network, vol. 24, no. 4, P 19-24, July, 2010. https://www.researchgate.net/publication/220553808

2. H. Witti, C. Ghedira, E. Disson, and K. Boukadi. Security governance in the multi-cloud environment:A systematic mapping study, in 12th World Congress on Services (SERVICES'16), USA, 27 June-2 July 2016. https://ieeexplore.iee.org/abstract/document/7557398/sim ilar\#similar

3. P. Arora, R. C. Wadhawan, and E. S. P. Ahuja. Cloud computing security issues in infrastructure as a service, International Journal of Advanced Re-search in Computer Science and Software Engineering, vol. 2, no. 1, 2012.

4. W. Huang, A. Ganjali, B. H. Kim, S. Oh, and D.Lie. The state of public infrastructure-as-a-service cloud security, ACM Computing Surveys, vol. 47, no. 4, June, 2015.

https://security.csl.toronto.edu/papers/whuang_csur2015. pdf

5. J. Singh. Cyber-attacks in cloud computing: A case study, International Journal of Electronics and Information Engineering, vol. 1, no. 2, PP.78-87, Dec. 2014.

6. B. M. Mehrdad, N. Soheil. Cloud Computing: Changing Cogitation about Computing, World Academy of Science, Engineering and Technology, p1112-1116, 2009.

http://citeseerx.ist.psu.edu/viewdoc/download?doi=10.1. 1.309.1337\&rep=rep1\&type $=$ pdf.

7. E. D. Dorothy, Loganscott. Location-Based Encryption \& Its Role in Digital Cinema distribution, Proceedings of ION GPS/GNSS, 2003.

8. W. Cong, W. Qian, R. Kui). Ensuring Data Storage Security in Cloud Computing, 17th International Workshop on Quality of Service, USA, 13-15 July 2009. Available at: http://ieeexplore.ieee.org/xpl/login.jsp?tp=\&arnumber $=5$ 201385\&url=http\%3A\%2F\%2Fieeexplore.ieee.org\%2Fie 15\%2F5201378\%2F5201379\%2F05201385.pdf\%3Far number\%3D5201385.

9. C. Jarabek. A Review of Cloud Computing Security: Virtualization, Side-Channel Attacks and Management, Department of Computer Science, University of Calgary, 2011.

http://people.ucalgary.ca/ cjjarabe/papers/jarabek_cloud _security. pdf

10. H. Doug. A Survey on the Security of Virtual Machines, April 21, 2009. Available at: http://www1. cse.wustl.edu / jain/cse571- 09/ftp/vmsec.pdf.

11. K. 'Shade O., I. Frank, A. Oludele. Cloud computing security issues and challenges, International Journal of Computer Networks (IJCN), Vol 3. Issue 5, Dec, 2011. 
12. J. Bethencourt, A. Sahai, and B. Waters.

Ciphertext-Policy Attribute-Based Encryption, IEEE Symposium on Security and Privacy (SP '07), USA, 20-23 May, 2007.

https://ieeexplore.ieee.org/document/4223236

13. K. J. Omer, A. Safia, M. S. El-Horbaty and M. S. Abdel-Badeeh. Efficiency of Modern Encryption Algorithms in Cloud Computing, International Journal of Emerging Trends \& Technology in Computer Science, vol.2, no.6, 2013.

https://ijettcs.org/Volume2Issue6/IJETTCS-2013-12-2 5-095.pdf

14. T. M. Nidal, T. A. Anas, M. R. Shadi. Cloud

Computing Challenges and Solutions, International Journal of Computer Networks \& Communications (IJCNC), Vol.5, No.5, 2013.

15. D. Lingkiswaran, S. S. Sugalia, T. Rajermani. Cloud Computing in Healthcare, International Journal of Students' Research In Technology \& Management, Vol 5, No 1, p209-216, Sep 2017.

16. P. Stakes, Cloud Computing, 2017. http://en.wikipedia.org/wiki/Cloud_computing.

17. S. RAO V, N. RAO N K, E. KUSUMA KUMARI. Cloud Computing: An Overview, Journal of Theoretical and Applied Information Technology, Vol. 3, Issue 3, 2012. http://www.jatit.org/volumes/research-papers/Vol9No1 /10Vol9No1.pdf

18. A, Anca, P. Florina, U. Geanina, S. George, T. Gyorgy. Study on advantages and disadvantages of Cloud Computing - the advantages of Telemetry Applications in the Cloud, Recent Advances in Applied Computer Science and Digital Services, ISBN: 978-1-61804-179-1, 2013.

19. M. Akbar Rivai, G. Wang. Cloud Computing Platform Services in the University Libraries for Digital Repository, International Journal of Advanced Trends in Computer Science and Engineering, Vol. 9, No.1, January - February 2020. http://www.warse.org/IJATCSE/static/pdf/file/ijatcse43 912020.pdf

20. A. B. Singh, V. Vasanthi, M. Hemalatha. A Brief Survey on Architecture, Challenges \& Security Benefit in Cloud Computing, International Journal of Information and Communication Technology Research, Vol. 2 No. 2, P102-111, February 2012.

http://citeseerx.ist.psu.edu/viewdoc/download;jsessioni $\mathrm{d}=\mathrm{E} 3 \mathrm{~B} 6 \mathrm{~B} 9 \mathrm{EFBA} 841374 \mathrm{D} 2 \mathrm{D} 572033 \mathrm{BA7109E}$ ?doi=10 1.1.301.9766\&rep=rep1\&type $=$ pdf

21. I. Olga Vaganova, , V. Zhanna Smirnova, , V. Ekaterina Vovk, , A. Anastasia Kapina. Comparative analysis of Cloud Technologies, International Journal of Advanced Trends in Computer Science and Engineering, ISSN 2278-309,1 Vol 9, No.3, May - June 2020. http://www.warse.org/IJATCSE/static/pdf/file/ijatcse129 32020.pdf 